\title{
HOMEM E NATUREZA EM HENRIQUE DE GAND: UMA MUDANÇA DE RUMO NA ANTROPOLOGIA AUGUSTINISTA
}

\author{
Mário S. de Carvalho*
}

\begin{abstract}
SÍNTESE - Depois de J. Gómez Caffarena, de C. Bérubé e de R. Macken, sobretudo, terem insistido numa leitura augustinista da antropologia henriquina, a nossa contribuição (mais sistemática do que histórica) pretende antes retirar as consequências da correcção do augustinismo que, por meio do avicenismo, Henrique de Gand levou a cabo. Propomos uma leitura da natureza (natura) na sua especificidade metafísica, de anterioridade em relação ao universal e ao singular, tendo como efeito uma antropoteologia que é uma verdadeira mudança de rumo do augustinismo como uma quota-parte para a Modernidade. Ilustraremos a nossa tese insistindo: na situação histórica de Henrique, no seu programa metafísico-crítico, na doutrina da relação e na da individuação. Os textos abordados serão da Summa, dos Quodlibet e da Lectura ordinaria. Finalmente, apontaremos para um horizonte contemporâneo em que a antropologia deve ser refeita na relação com a natureza. Por outras palavras: a natureza do homem não pode passar sem aquilo que faz o homem um ser de natureza. Foi precisamente isto que Henrique de Gand esqueceu devido ao seu avicenismo, mas não menos ao seu augustinismo de que é (como afirmaram os três intérpretes citados) fundamental nele.
\end{abstract}

PALAVRAS-CHAVE - Augustianismo. Avincenianismo. Henrique de Grande. Homem. Natureza.
ABSTRACT - Following the incisive works by $\mathrm{J}$. Gómez Caffarena, C. Bérubé and especially R. Macken on the Augustinian reading of Henrique de Gand's anthropology, our contribution (more systematic than historical) seeks rather to draw the consequences of the correction of Augustinianism which Henrique de Gand undertakes, by means of Avicennianism. We propose a reading of nature in its metaphysical specificity of anteriority in relation to the universal and singular, resulting in an anthropotheology which is a veritable shift of Augustinianism towards modemity. We shall illustrate our thesis by insisting on Henrique de Gand's historical background, his metaphysical, critical program, his doctrine of relation and individuation. The texts studied are the Summa, the Quodlibet and the Lectura ordinaria. Finally, we indicate a contemporary horizon in which anthropology has to be reworked in relation to nature. In brief, human nature cannot overlook what makes man a being of nature. This was precisely what Henrique de Gand forgot, due to his Avicennianism, but also due to his Augustinism (as affirmed the three interpreters mentioned above) which is fundamental to him. KEY-WORDS - Augustinianism. Avicennianism: Hennique de Gand. Man. Nature.

* Universidade de Coimbra (Portugal). E-mail: marcarv@condor.ci.uc.pt

\begin{tabular}{|l|l|l|l|l|l|}
\hline VERITAS & Porto Alegre & v. 44 & n. 3 & Setembro 1999 & p. 679-694 \\
\hline
\end{tabular}


O programa hodierno de um macromodelo ecológico (no mais vasto sentido originário grego de 'eco-logia', i. e., muito para além da mera oposição diametral a um modelo tecnológico) não nos deixa ler os dois substantivos do título desta comunicação -homem e natureza - em termos disjuntivos, mas sim de uma forma complexa em que a copulativa é chamada a traduzir uma relação na diferença, uma união dos diferentes. Propostas ecológicas ou holísticas nas quais a antropologia, seus discursos e programas, se formulam na interrelação crítica do singular e do universal, do sensivel e do inteligivel, do local e do global, do homem e da natureza, conjuntamente com uma tomada de posição que simultaneamente se alimente da vida e a alimente também, estão nos antípodas da dissociação moderna entre homem e natureza, duas res que se definem pelo pensamento e pela extensão, finalmente responsáveis pela urgência de uma "nova aliança". Digamos, para que tudo seja claro desde o início, que um qualquer desafio de pensar o homem fora da relação com a natureza carregada de sentido e desta sem aquele nos parece um equívoco programático, para não dizer mesmo um infeliz inviesamento. Porém, é imperioso que esta relação primordial não chegue a ser equacionada independentemente de uma tomada de posição perante aquilo que aqui consideraremos ser um desafio sempre em aberto: a compreensão da relação ho$\mathrm{mem} /$ natureza, sem ser vertical, não deve eximir-se ao Diferente (o que nem é homem nem natureza) que torna possivel a própria relação que se pretende reatar de um modo não colonizador. Isto é: a equação da relação perdida há-de tornar o homem mais humano, como também a natureza mais natural, mas este "tornar-se o que cada coisa já é" só garantirá a indissociabilidade de cada um dos relata se for pensado no que eles têm em comum. Para tal exige-se a sua diferenciação frente ao advento radical de sentido.

É claro que o leitor contemporâneo do teólogo flamengo Henrique de Gand (m. 1293) depara-se com uma dificuldade real que em certa medida lança este autor para o oblívio de um passado que já nada diz. ${ }^{1}$ Jamais se poderá confundir o homem - a criatura mais digna do Universo, cujo papel conjuntivo realiza no entanto o laço entre dois mundos $(0.3,16)$ - com a physis. Recusa-se combinar ontologicamente homem e natureza à maneira grega antroponaturalista na qual o homem ganha o seu significado e interpreta o seu horizonte na imergência numa physis radical. Tudo é diferente e não poderia senão sê-lo: o significado do homem interpreta-se à luz inconfundível de uma sobrenatureza. A natureza do homem parece assim esgotar-se no diálogo tão cativante como exigente com Deus, ao ponto de a sensibilidade para com a natureza poder aparecer como supérflua. Desde muito cedo na sua carreira teológica o autor criticará Aristóteles pelo facto de não ter visto que falar da natureza do homem não é o mesmo que falar do

No decurso deste trabalho, e por razões de economia, citamos as principais obras de Henrique de Gand, sem mais, recorrendo às abreviaturas Q. e S., respectivamente para os Quodlibet e para a Summa, imediatamente seguidas da indicação do número do Quodlibet (e da questão) ou do número do artigo da Summa (e da respectiva questão), terminando com a referência das páginas (no caso de existir já a edição crítica de Lovaina, Henrici de Gandavo Opera Omnia) ou dos folia (para o caso da edição princeps de J. Badius). 
homem de natureza. Esta tese nunca a abandonará - no Quodlibet 12, q. 13 ainda continuará a dizer que o erro dos filósofos está na ignorância da sobrenatureza, no caso acerca dos fins do homem ${ }^{2}$ - maś subestimar a imersão do homem na natureza não tem a sua exacta contrapartida no diálogo com a sobrenatureza, sobretudo quando este diálogo, como é o caso, é orientado também por uma antropologia obstinada no rigor e exaustão discursivas. Encontramos, é certo, magníficas sugestões em Henrique de Gand passíveis de fecundar uma antropologia dinâmica preocupada com o sempre imprescindivel laço entre o homem e Deus. Mas ao autor não é estranha uma direcção moderna que, à força de pensar a natureza do homem, o distancia da natureza que é uma necessidade - como começámos por dizer - para o repensar do homem.

$\mathrm{O}$ efeito mais imediato deste distanciamento não se recorta na natureza tal como hoje em dia a entendemos vulgarmente, mas prende-se logo com o que poderiamos chamar as condições naturais do homem (em contraponto às meramente intelectuais que convém em qualquer caso não dissociar) e que em linguagem post-diltheyana poderiamos denominar como "formas de vida". De uma maneira mais peremptória e num tom axiomático sempre diremos, para começar, que não haverá antropologia sem uma ontologia da natureza sensível ao sentido de que ela está inevitavelmente prenhe, isto é dizer, sem uma experiência humana da natureza.

Para quem adopta o itinerário augustinista concentrado no estudo da alma e de Deus (Sol. 1, 7) é inevitável que a atenção à natureza, no sentido de mundo ou universo cosmos, fique em segundo plano ou seja mesmo esquecida. ${ }^{3}$ Acresce que a interpretação cristã do cosmos, como sabemos depois de R. Bultmann, é sobredeterminada pela visão segundo a qual "o mundo é um mundo humano constituído pelo homem".

Embora ainda não esteja feito o levantamento às referências de Henrique de Gand à natureza é claro que este foi um tema que não o motivou grandemente. Há, portanto, razões, além das mais directamente de ordem augustinista, que explicam a omissão: no quadro metafísico adoptado pelo autor, ens creatum substitui não só natura, ou mesmo mundus, como de alguma forma abafa a sua eclosão sob o manto de um ente cujo sentido se resolve num horizonte criatural que mais do que ser sensivel aos diferentes dá antes importância maior à partilha de uma mesma condição, a de estar frente ao Criador correspondendo-Lhe (crea-

2 O. 12,13 , f. 493 r X: "[...] etsi Philosophus circa ea quae sunt ad finem, multa secundum rectam rationem sentiebat et illa quae sentit fides catholica, circa illa tamen in ordinando ipsa ad finem, et circa ipsum finem vitae humanae in multis errabat, sicut et alii philosophi quia, ut dicit Augustinus, sibi ipsi fabricabant quandam felicitatem percipiendam in vita praesenti, quae est finis operum virtutis, et sic ad alium finem ordinabant virtutum opera quam ordinet fides catholica quae ordinat illa ad beatitudinem percipiendam in vita futura. Et sic erravit."; vd. também $0.15,9$, f. 531 r Q - v 0 .

Cf. ORTEGA Y GASSET, J. - En torno a Galileo, Madrid, 1982, 160-162.

ARENDT, H. - Der Liebesbegniff bei Augustin (trad. port.: Lisboa, 1997, 75). 
tura mundi). ${ }^{5}$ Semelhante perspectiva não podia deixar de aguçar a problemática da relação para a qual o Cristianismo muito contribuiu, apesar de nos irmos deparar sobretudo com um autor obcecado pela rigorosa determinação das condições que possibilitam essa correspondência. Em contrapartida ao esquecimento da natureza e de qualquer uma das suas fulgurações, no latim henriquino, "natura" é uma palavra que tem um relevo enorme, porém distinto: "[...] natura proprie appelatur quidditas et essentia rei. ${ }^{n 6}$ A sua fonte é, aqui, o avicenismo sobretudo na identificação ontológica de um plano que não seja nem universal nem singular mas anterior ou prévio a essas duas ordens (Logica I). Ora, é de uma vital importância o papel da "natura" enquanto factor de correcção do jeito augustinista de praticar a filosofia com temor e tremor (0. 13, 9 e Q. 15, 9). Concordamos, por isso, em que Henrique de Gand encontrou em Avicena o veículo adequado para trazer o rigor que faltava à filosofia matricial de St. Agostinho. ${ }^{7}$ Mas havia que interpretar esta profunda opção e é para isso que nos propomos agora contribuir num quadro hermenêutico apenas parcial. A nossa conclusão será a de que a natureza que verdadeiramente interessa ao teólogo de Gand é a natura metafísica na qual o discurso (e por isso também o discurso sobre o homem) devém rigor. Uma opção tão moderna como esta, não obstante todas as suas indiscutíveis virtualidades, padece hoje em dia de falta de pertinência programática enquanto contributo para o quadro teórico com o qual começámos este texto.

\section{3}

O doutor de Gand pensa digna e comprometidamente após Tomás de Aquino. Esta situação histórica não é desprovida de importância. Ele foi mesmo o primeiro mais autorizado crítico de Tomás. Isto quer dizer: Henrique pensa teologicamente depois de o Ocidente e a teologia cristã haverem descoberto e assimilado de alguma forma o majestoso manancial do pensar aristotélico. Hoje em dia é, por isso, cada vez mais consensual o facto de que, não obstante ter participado na comissão de Tempier (Q. 2, 9, p. 58, p. 61), Henrique conhece e acima de tudo respeita Aristóteles. Há intérpretes que têm notado com pertinácia o facto de haver disparidades entre o membro da comissão de Tempier e algumas das suas teorias filosófico-teológicas. ${ }^{8}$ Não é verdade que no início da sua carreira como teólogo (S. 1, 4 , f. $12 \mathrm{vE}$ ), ele quis mesmo repetir o gesto helenista (que o Renascimento fará seu) de harmonizar Platão e Aristóteles sob a égide de Agostinho?

5 Cf. CARVALHO, M. S. de - "Creatura Mundi". Estudo sobre o contexto metafísico da argumentação de Henrique de Gand contra a possivel etemidade do mundo ('Quodlibet' I, q. 7-8). Dissertação de Doutoramento FLUC, Coimbra, 1994.

Q. 4, 4, 90 v A. Também: S. $28,5,168$ v B: "[...] naturam hic appelamus essentiam rei et quidditatem dictam nomine absoluto, quae dat esse rei quam significat definitio."

7 Cf. MACKEN; R. - "Henry of Ghent and Augustine" in "Ad litteram": Authoritative Texts and Their Medieval Readers. Ed. M. D. Jordan \& K. Emery, Notre Dame London 1992, 251-74; ID. - "Henri de Gand et la pénétration d'Avicenne en Occident", in Philosophie et Culture. Proceedings of the XVIIth World Congress of Philosophy, ed. V. Cauchy, Montréal, 1988, III, 845-50.

Cf. PORRO, P. - "Possibilità ed 'esse essentiae' in Enrico di Gand", in Henry of Ghent. Proceedings of the International Colloquium on the Occasion of the 700th Anniversary of His Death, ed. W. Vanhamel, Leuven, 1996, 252-53. 
Como sabemos, a entrada de Aristóteles representou, entre outras coisas, a possibilidade de uma autonomização filosófica e de uma horizontalização antropológica que depressa promovia, entre outras coisas, a acessibilidade da felicidade humana mediante uma pura contemplação terrena. ${ }^{9}$ Segundo o denominado, por Gauthier, "aristotelismo integral", a felicidade mental ou especulativa ou teórica, enquanto humanismo filosófico que visava a realização perfeita da eudaimonia (humana) à medida da vida terrestre ou civil, era uma possibilidade real aberta ao homem capaz de perseguir o ideal do livro X, 7-9 da Ética Nicomaqueia. ${ }^{10} \mathrm{O}$ De Summo Bono de Boécio dava corpo a este ideal. Mas - repare-se - de facto não é apenas Aristóteles, como já disse, e Boécio que caem sob a mira de Henrique. Encontramos também uma crítica àqueles "vãos teólogos" (certamente Tomás de Aquino) que perante a questão antropo-teleológica empregavam sem o devido cuidado o termo beatus em relação ao ser humano. "Enfim, a condição religiosa do homem era, naturalmente, assunto intraconfessional mas não menos o seria problema intradisciplinar. Várias alternativas estavam em aberto para a antropologia teológica.

\section{4}

Mas comecemos pelo princípio. Num complexo e tenso cenário históricofilosófico Henrique intervém repetindo a inquietação augustinista em relação àquele grupo de pensadores (fossem relativistas fossem cépticos) que ameaçavam mais ou menos esgotar o real no sensivel confundindo intelecção e sensação, conhecimento empírico e científico. "A causa do erro - escreve o nosso teólogo sem margens para quaisquer ambiguidades - está na identificação entre intelecto e sensação e numa interpretação da ciência como oriunda dos sentidos" (S. 1, 1, f. 2rC). Não nos interessa agora ponderar a objectividade desta sua critica histórica, mas analisá-la ou lê-la como um facto reconhecido adentro do horizonte hermenêutico apresentado atrás.

Para Henrique existe uma evidência natural e universal de saber que não pode ser defraudada: manifestum est quod contingit hominem scire aliquod (S. 1, 1, f. 1vB). Como notou Gómez Caffarena na interpretação dos passos iniciais metodológicos ou programáticos da Summa, Henrique não se limita apenas a repetir - Contra Academicos de Cícero, mas tanto quanto nota a importância da acção humana assente numa ciência certa também lembra, na companhia de Aristóteles, que o princípio do conhecimento é dotado de uma naturalidade ontológica indisfarçável: "todos os homens desejam por natureza saber" (Metaph. I, 980a). Ao

9 S. 49,5 , f. 35vF: "Ex qua consecutione philosophi ponebant in homine beatitudinem duplicem secundum duplicem consecutionem illius: unam politicam circa actionem boni moralis; aliam speculativam - et illam esse supremam - circa speculationem veri secundum scientias speculativas. Et in isto modo in superion effigie et similitudine consequuntur homines illud bonum, sed in infimo gradu beatitudinis"

10 Cf. GAUTHIER, R.-A. - "Trois commentaires averroistes sur l'Éthique à Nicomaque" AHDLMA 16 (1948), 279.

${ }^{11}$ Cf. CELANO, A. J. - "Act of the Intellect or Act of the Will: The Critical Reception of Aristotle's Ideal of Human Perfection in the 13th. and early 14th. Centuries", AHDLMA 57 (1990), 103-110, sobretudo para S. 49,3 a 7 . 
fazer assentar neste axioma qualquer acção que torne o homem humano, ${ }^{12}$ a correç̧ão do intelectualismo feita por Agostinho é revalidada e situada de novo na agenda filosófica de Trezentos. O fim do homem carece do conhecimento do ser e da verdade, mas, acima deste conhecimento, está a posse amorosa quer do ser quer da verdade. É óbvio, assim, que a antropologia teológica de Henrique de Gand visa ser uma alternativa histórica à proposta de Tomás de Aquino.

Está assim esboçado o horizonte do homem, um ser que começa a conhecer pelos sentidos (S. 1, 1, f. 1vB), mas que se abre de forma natural à única realidade que verdadeiramente os supera, Deus. Se o desejo de saber não é defraudável negá-lo equivaleria à destruição da fé e da filosofia (S. 1, 1, 1vD e 3rF) - no itinerário que acabámos de traçar impressivamente nota-se acima de tudo uma afinidade augustinista que por si só não poderia justificar o nosso interesse pelo teólogo de Gand. Tratar-se-ía, no caso, de uma mera repetição histórica tanto quanto como fomos avisados por Ortega y Gasset - a diferença histórica autoriza a repetição do mesmo. É certo que não é de somenos importância insistir na teoria antropológica do ser-à-imagem de $\operatorname{Deus}^{13}$ ou no tríptico anímico memória/inteligência/vontade (desde a Lectura. Ordinaria essas teorias estavam conquistadas pelo autor). ${ }^{14}$ Mas o que há de específico no contributo henriquino é, precisamente, o plano da "natura hominis" tomando a expressão na vertente de rigor ou de correcção do augustinismo a que começámos por aludir.

A antropologia de Henrique de Gand é, por isso, metafísica tomando esta o ideal de uma strenge Wissenschaft.

Dado que Gómez Caffarena e C. Bérubé ou R. Macken, ${ }^{15}$ principalmente, insistiram muito bem (sobretudo o primeiro ao dar o mote à interpretação) na dominante da belamente chamada "metafísica da inquietude humana" - que vê no homem fechado em si, monodimensional (intellectio qua intelligit se), a absoluta irrealização da fundamental quietação do desejo ontológico (intellectio É qua mens intelligit Deum omnino quietat ipsum: 0. 15, 9, f. 581rC) - gostaríamos de apontar noutra direç̧ão. Não se substimará essa inquietude posto ser claro para Henrique que o homem está mais centrado em Deus do que em si mesmo (S. 4, 9, f. 39vV), ${ }^{16}$ trata-se sim da sua elevação a problema digno de ser fundado. Veremos que houve um preço a pagar por esta transformação da inquietude em rigor.

12 Cf. GOMEZ CAFFARENA, J. - Ser participado y ser subsistente en la metafisica de Enrique de Gante, Roma, 1958, 12.

13 Cf. ROVIRA BELLOSO, J. M. - La visión de Diós según Enrique de Gante, Barcelona, 1960, 155-165.

14 Lectura Ordinaria Super Sacram Scripturam, p. 156-60: "Haec est [...] praecisa causa, quare homo secundum interiorem hominem est ad Dei imaginem, quia scilicet per sapientiam secundum ipsum capax Dei est, secundum quod dicit Augustinus..." Sobre o estado da questão autoral, vd. CARVĄLHO, M. S. de - "La pensée d'Henri de Gand avant 1276: Les erreurs concernant la création du monde d'après la 'Lectura Ordinaria Super Sacram Scripturam'", Recherches de Théologie ancienne et médiévale 63 (1996), 36- 67. Cf. BÉRUBÉ, C. - "Dynamisme psychologique et existence de Dieu chez Jean Duns Scot, J. Maréchal et B. Lonergan", Antonianum 48 (1973) 12-13, 30.

16 Cf. GOMEZ CAFFARENA; J. - "Metafisica de la inquietud humana em Enrique de Gante", in $L$ 'homme et son destin d'après les penseurs du Moyen Age. Actes du Premier Congrès International de Philosophie Médiévale, Louvain Paris, 1960, 633-34. 
A fim de realizarmos a nossa intenção há que relembrar rapidamente - imperativo que nos perdoarão - algumas prévias noções básicas da metafísica henriquina. $\mathrm{O}$ autor opõe ao purum nihil a res -como noção apriórica avicenizante - e neste plano da res distingue, sobretudo epistemologicamente, entre o puro mental (res a reor reris dicta) e o possível alético (res a ratitudine: 0. 7, 1, p. 27; S. 24, 3, f. $138 \mathrm{vO}$ ). A relevância deste último prende-se à sua "diversidade" ontológica, pois é no seu seio que nos deparamos com a célebre estratificação ou modalização que vai do que realmente existe, quer na mente quer no singular concreto (res existens in actu), ao que se pode pensar como possivel de existir, sem que tenha forçosamente de existir, pelo facto de corresponder a uma ideia de Deus (O. 6, 3, p. 49; Q. 3, 9, f. 60rV). Abreviando na terminologia mais comum: tudo o que de facto participa do ser (esse) ou é dito possuir um ser de essência (esse essentiae) ou um ser de existência (esse existentiae). Não há alternativa, um tertium qualquer, mas a distância entre esse essentiae e esse existentiae é a mesma que encontramos entre aquilo que se (Deus) pensa com correcção onto-lógica (a retitudo de St. Anselmo ${ }^{17}$ ) e aquilo que se (Deus) decide efectivar por um acto radical da vontade (liberdade), ${ }^{18}$ ohne warum. Distingamos tão-só metodicamente os dois planos que alguns tendem a radicalizar. No esse essentiae a criatura tem o seu primeiro modo de participação em Deus (daí poder-se falar da sua eternidade, verdade ou necessidade) -Henrique define-o (0. 10, 8, p. 201) como uma "participação na essência do ser divino [...] no plano da causalidade formal" - no esse existentiae (temporal, falso e contingente) trocamos o plano da exemplaridade pelo da efectividade, effectus divinae essentiae ou ratio causae efficientis (Q. 10,7, p. $\left.151^{19}\right)$. Traduzindo isto relativamente à essência humana e no âmbito histórico-polémico que foi o do autor, dir-se-á que o principal erro dos filósofos foi o de não terem percebido o carácter radicalmente temporal e livre da criatura in esse existentiae.$^{20}$ Liberaliter, non naturaliter, diz o texto citado em nota. Isto significa que os filósofos (Avicena, no caso) perceberam bem a necessidade do rigor e o seu plano esse essentiae, mas ignoraram que a essência do homem não pode ser estranha à liberdade com que foi criado. Não se trata de substituir o necesse esse grego pelo possibile esse per se, necessario ab alio avicenista, mas, mais radicalmente, trata-se de chegar a pensar com o rigor possível o possibile esse per aliud. ${ }^{21}$

17

18

Cf. S. 21,4 , f. $127 \mathrm{rO}$; S. 34, 2, p. 175-176; Q. 5, 2, f. 154rD.

Cf. CARVALHO, M. S. de - "Para a Histónia da Possibilidade e da Liberdade. João Duns Escoto, Guilherme de Ockham e Henrique de Gand", Itinerarium 40 (1994), 145-180.

Cf. ainda: 0. 10, 8, p. 202; S. 21,4 , f. $127 \mathrm{vS}-128 \mathrm{rS}$; S. 21,3 , f. 126vG; 0. 11, 3, f. 449rG.

S. 63,2 , fol. 197vF: “... essentia humana in quantum est exemplatum secundum rationem ideae ipsius divinae essentiae, se habet ad Deum sicut actum et institutum in esse essentiae, et postmodum ab ipso Deo in esse existentiae est productum, non naturaliter a divina essentia, sicut ponebant philosophi, sed liberaliter a divina voluntate determinante semet ad creaturae productionem in esse existentiae." Também 0. 5, 4, f. 159rR, e Henrique de Gand.Sobre a Metafisica do Ser no Tempo (Questões Quodlibéticas $I, 7 / 8-9$ e 10). Edição bilingue. Versão do latim, introdução e notas; Prefácio e restabelecimento crítico do texto latino de Raymond Macken, Lisboa, 1996.

Cf. PORRO, P. - "Possibile ex se necessarium ab alio. Tommaso d'Aquino ed Enrico di Gand", Medioevo 18 (1992) 231-73; ID. - "Possibilità...", 211-253, como um óptimo contraponto a uma interpretação demasiadamente existencial e temporalista. 
Aos ouvidos educados na escola aquinatense, esse essentiae poderia soar a princípio de limitação. Ora, não é isso que se passa com Henrique. Como salientou há já muito tempo J. Paulus, o facto de o ponto de partida da metafísica henriquina ser o ente cuja realitas faz abstracção da existência (e por isso mais Sachheit do que Wirklichkeit) assinala uma opção essencialista, ${ }^{22}$ mas - complete-se a reflexão de Paulus - a sua efectivação (Wirkung), radicalmente temporal e livre, impõe-lhe um tipo de dinamismo desconhecido para o tomismo. Raymond Macken propôs, por isso, que se falasse de um "dinamismo essencial" já que ao carácter estático das essências criadas (no tomismo), a sua imutabilidade em Deus não impede (diremos mesmo que funda) a sua realização dinâmica no sentido de uma maior ou menor autenticidade histórica e existencial. ${ }^{23} \mathrm{~A}$ assimetria existente entre uma perspectiva sub specie aeternitatis (impossivel ao homem in via) e uma outra sub specie temporis, faz com que o esse essentiae só possa ser eterno, necessário ou verdadeiro na perspectiva intelectual de Deus e, portanto, na ordo temporis ele é chamado a fundar uma dialéctica "teo-lógica" ascendente; por outro lado, a temporalização ou efectivação do possível pela Criação ex nihilo et in tempore é propulsionadora de um conatus idealista e histórico, uma verdadeiro dinamismo de (in-)finitude que ao assentar no não-ser (non esse) essencial da criatura (0. 1, 7-8), quadra perfeitamente com os textos levantados por Gómez Caffarena na linha do Inquietum est cor nostrum..$^{24}$ Sublinhe-se bem: o plano do esse essentiae é aquele por sobre o qual a metafísica se constitui na ordem da ciência não na ordem do tempo. No discurso científico humano o começo só pode ser temporal e contingente mas aspira a deixar de o ser tanto mais que essa aspiração não é ontologicamente defraudável, conforme vimos.

22

23

24

Cf. PAULUS, J. - Henri de Gand. Essai sur les tendances de sa métaphysique, Paris, 1938, 24.

Cf. MACKEN, R. - "La théorie de l'illumination divine dans la philosophie d'Henri de Gand", Recherches de Théologie ancienne et médiévale 39 (1972), 107.

S. 4, 5, f. 33rE - vE: "Absolute ergo dicendum, quod homo appetit scire ea quae rationis naturalis notitiam excedunt, ita quod per naturam quiescere non potest humanus appetitus quousque deveniat ad apertam notitiam separatorum, maxime quidditatis et essentiae eius qui est prima veritas, ita quod nihil citra ipsam sedare posset eius appetitum, etiam si videat clare omnes substantias angelicas, immo tunc amplius eius desiderium ad nudam divinam essentiam videndam excitaretur quanto propinquior esset fini, et ei magis assimilaretur, secundum quod videmus corpora moveri ad loca sibi naturalia, et tanto velocius moveri quanto magis propinquant fini. Nollum ergo firmiter scibile potest quietare appetitum hominis in sciendo, sed solum infinitum in summo cardine rerum constitutum. Cum enim anima naturaliter capax sit summi boni per affectum et summi veri per intellectum, minori impleri non potest, quia quod potest capere maius, non potest impleri minon, sed semper remaneret aliquid de vacuo quod appeteretur implen, et ita adhuc etiam non esset quies". Q. 15, 9, f. 581rC: "Contra. Illa operatio essentialior et principalior est operanti, quae omnino quietat ipsum ne queat moveri ad aliud operando circa illud, quam quae non quietat ipsum, quia non est motus nisi propter quietem, secundum Commentatorem super VIII ${ }^{\circ}$ Physicorum. Sed intellectio qua angelus aut mens intelligit Deum, omnino quietat ipsum, non sic intellectio qua intelligit se, dicente Augustino in principio libri Confessionum: 'Domine, fecisti nos ad Te, et inquietum est cor nostrum donec requiescat in Te.' Ergo etc."; cf. GÓMEZ CAFFARENA, J. - “Metafisica...", 629. 
Basta quanto ao ponto de partida da metafísica, mas deve imediatamente reconhecer-se que ela equilibra com dificuldade dois planos bem distintos. ${ }^{25}$ Agora há que ver como no lexema "natura hominis" o complexo metafisico-avicenista "natura" dá rigor ao genitivo material. Mais uma vez só se pode fazê-lo contrapondo este programa à proposta de São Tomás de que Henrique se quis distanciar depois de a conhecer e respeitar. ${ }^{26}$ Há um texto-chave nesta distância que passa por ser uma retoma da problemática teológica dos nomes divinos mas onde se dá conta da relação arquifundamental Deus/mundo (Q. 9, 1, p. 8-10): Deus pode ser chamado criativo (creativus) e a criatura criável (criabilis) graças ao ordo habitudinalis que desde toda a etemidade se encontra na vontade, no intelecto e nas rationes ideales divinas; mas de Deus se pode dizer ainda que há-de criar (creaturus), bem como da criatura, que deve ser criada (creanda), pois há um ordo actualis em Deus em relação ao futuro ligado ao modo como a vontade decide, livremente, desde toda a etemidade, sobre qual das essências possíveis se vai exercer; e, por fim, Deus só é criador (creator), e a criatura realmente criatura (creatura), no momento em que intervém no tempo pela efectivação. Surpreendem-nos, sem dúvida, estas distinções, mas elas não se explicam unicamente pelos condicionamentos metodológicos inerentes a uma quaestio. Elas limitam-se a desenvolver o ponto de partida filosófico-teológico do nosso autor. Atente-se, como é devido, no facto de, quer no plano do ordo habitudinalis quer no do ordo actualis, a gramática da relação estar presente embora, como é natural, dado o homem se constituir como um ser que inicia a sua actividade cognitiva pelos sentidos, a sua concretização só se poder falar (i.e. fazer sentido) quando o nome Creator substitui positivamente o nome de Creativus ou de Creaturus. De notar, em qualquer caso, a importância destes dois últimos nomes na medida em que eles revelam como o problema teológico da Criação apela como seu lugar de possibilidade fundacional ou lógica para uma condição metafísica que não quer fugir ao rigor embora se prenda (como sabemos) em distinções subtilíssimas que visam ver mais claro.

O desafio de trazer rigor à antropologia metafísica não seria tarefa de pouca monta e nesta altura já se pode perceber que ele deve incidir num contributo para a estrutura ontológica da relação. Uma vez que o homem é também impressivamente imago Dei e metafisicamente o produto nadificado (non esse) de uma essência contrastante, ele não pode pretender ser compreendido, respectivamente, nem só nas marcas do esse existentiae nem só nas do esse essentiae. Assim sendo, segundo Henrique, no que é uma superação do substancialismo aristotélico, qualquer criatura deve ser subsistente em si mesma (aliquid ad se) e ao mesmo tempo algo de relativo ou relacionado com outrem (aliquid ad se ab alio). ${ }^{27} \mathrm{De}$ facto, a criação no tempo institui hic et nunc uma relação da creatura mundi com Deus cujo fundamento onto-lógico terá de ser o da relação lógica que traduz a constituição primordial de Deus para com a criatura. ${ }^{23}$

${ }^{25}$ Cf. PORRO, P. - Ennico di Gand. La via delle proposizioni universali, Bari, 1990, 139.

${ }^{26}$ Cf. HOEDL, L. - "Introduction à l'édition critique de la 'Summa' d'Henri de Gand", in Henrici de Gandavo. Summa (Quaestiones ordinariae art. XXXI-XXXIV), Leuven, 1991, XIII-XIV.

27 Cf. DECORTE, J. - "Thomas Aquinas and Henry of Ghent on God's Relation to the World", Mediaevalia. Textos e Estudos 3 (1993), 106.

28

Cf. DECORTE, J. - "Thomas Aquinas...", 100-101: "God is in no way indifferent to creation: being related to the world, is constitutive of God's own essence insofar as its extemal activity is concerned." (É o autor que grifa). 
Ponderemos todo o capital teórico-crítico entretanto acumulado pelo facto de a metafísica aristotélica ser uma metafísica da forma centrada na substância (e onde, portanto, a relação é um modo menor de ser) e, por conseguinte, a alteração henriquina representar a superação de um paradigma substancialista por um criacionista ou criaturalista radical (i. e., mais 'dinâmico' ao nível existencial e mais 'lógico' ao nível ontológico). Em Tomás de Aquino, note-se, a apreensão da "criaturalidade" do homem era equacionada num quadro analógico em que a existência das criaturas analogava 0 acto de ser do próprio Criador. O padre MarieDominique Chenu chamou outrora a atenção, numa tão brevissima quanto célebre nota, para o elevado grau de positividade na noção de criatura que se extrai desta concepção tomasina. ${ }^{29}$ Mas ao nosso caso, aqui e agora, haveria que contrastar essa positividade com a permanente insistência henriquina na radical temporalidade do ser criado cujo correlato de rigor sonhado ou procurado passa por um vórtice de minuciosas distinções sensíveis entre os planos contrastantes. Apenas alguns exemplos: intentio de re/de esse; potentia subiective/obiective; res/ratio praedicamenti; esse aliquid per essentiam/per existentiam; exemplar/exemplatum; posse activum/passivum, que se divide ainda em posse activum Dei secundum se, posse passivum creaturae secundum se, posse passivum creaturae respectu Dei, posse activum Dei respectu creaturae, etc. ${ }^{30} \mathrm{O}$ não-ser da criatura (fora da relação assente na determinação da própria essência da criatura como tempo) corresponde a uma imagem de um Deus criador no tempo que decide frente a uma rede essencial à mesma medida que é um Deus interpessoal (Trindade) ou relação plena por essência. Era necessário, então, reformular a teoria da relação e, neste particular, a grande descoberta henriquina passa por haver percebido, muito para além de Tomás, a identidade entre subsistência e relação ou, se quisermos, em ter fundado o dinamismo no mais radical do ser. É este 0 alcance da transformação henriquina da teoria da relação e haverá, neste ponto, que lembrar as correcções que J. Decorte tem vindo a fazer à interpretação, porventura mais propalada de M. Henninger. ${ }^{31}$

Com efeito, para uma metafísica cristã ou criacionista, relatio e respectus são duas noções transformadas por Henrique (S. 35, 8) para dar conta do ser das criaturas que doravante não podem subsistir apenas pelo mero repetir poético da inquietude onto-psicológica que as Confissões traduziam de maneira soberba. Não é impunemente que se escolhe narrar a interioridade. ${ }^{32}$ Assim - e omitindo aqui o

Cf. CHENU, M.-D. - "La condition de créature" AHDLMA 37 (1971) 9-16.

Cf. PORRO, P. - "Possibilità..." 220-46, para o esclarecimento destas distinções.

Cf. DECORTE, J. - "Thomas Aquinas..."; ID. - “'Modus' or 'Res': Scotus' Criticism of Henry of Ghent's Conception of The Reality of a Real Relation", in Via Scoti. Methodologica ad mentem Joannis Duns Scoti. Atti del Congresso Scotistico Intemazionale, a cura di L. Sileo, Roma, 1995, 407-29; ID. - "Gilles of Rome and Henry of Ghent on the Reality of a Real Relation", Documenti e Studi sulla Tradizione Filosofica Medievale 7 (1996), 183-211; HENNINGER, M. J. - Relations. Medieval Theories 1250-1325, Oxford, 1989.

Cf. TAYLOR, C. - Les sources du moi. La formation de l'identité moderne, trad., Paris, 1998; THOMAE, D. - Erzaehle Dich selbst. Lebensgeschichte als philosophisches Problem, Muenchen, 1998, sobre os abusos da narratividade. 
complexo discorrer de Henrique sobre este assunto (talvez fosse sugestivo avançar que Henrique opera na filosofia como Bach, as fugas) ${ }^{33}$-, o nosso teólogo introduz a noção de respectus (que em portuguếs traduziriamos por "relação de respectabilidade") com o intuito de pensar a relacionalidade num plano metafísico em que a noção esse $a b$ altero coincide com o seu subiectum.

Noutro lugar já nos pudemos referir à correspondente crítica aos filósofos, designadamente ao facto de eles limitarem a categoria "relação" ao plano dos acidentes. A estes Henrique opõe (S. 32, 5, p. 116) a opinião dos teólogos que fundamentam a relação nas pessoas da Trindade, qui veram relationem realem funda$n$ vident in divinis personis super substantiam absque omni accidente. ${ }^{34}$ Por isso, agora basta-nos repensar o horizonte da nomenclatura categorial da relação (respectus) perante a da substância (ousía). ${ }^{36}$ Num horizonte substancialista a realidade mede-se numa hierarquia entre "ser-em-si" e "ser-em-outro" sendo que este comporta em relação àquele um carácter acidental e menor. Num horizonte relacional como é o do nosso autor, o "ser-para" (de notar que o correspondente henriquino é o "ser-de", esse ab ou abaleidade) concretiza-se, como vimos, pelo menos em dois planos (que de facto se desmultiplicam em perspectivas num esforço obsidiante de ver claro, se nos ativermos à exegese pormenorizada dos vários textos). Num - o da Trindade - há uma coincidência real entre substância e relação, de onde se extrai o modelo teológico do outro plano - o criatural, o único em que tem sentido falar-se em abaleidade - que no entanto pensa a relação na exterioridade (a participação extrínseca anunciada desde 0 . 1, 10) e, portanto, na irrealidade, aparência ou fenomenalidade (non esse). Considerado na perspectiva do real (Deus) qualquer relação exterior é, por isso, apenas "lógica" não real, i. é., ponto de vista. Mas para o que é visado não é indiferente - de facto, é constitutivo dele - o conteúdo que nele se visa. A relação é, assim, real (Wirklich), para ele (a criatura enquanto criatura), o que significa que no seu isolamento (no seu em-si) não há qualquer fulguração ou sentido. O par substância/acidente, ser-em-si e ser-em-outro foi substituído pelo par "ser-para" e "ser-em-outro", relação e acidente. Veremos a seguir como se conectam estes dois últimos pares. Compreender o que o homem é equivale a determinar o ligame da relação que lhe confere subsistência e esse ligame (ser-para) - por definição a coisa é agora clara - não pode ser só exclusivo a uma história concreta (esse existentiae) ele teve de ser fundado no plano mais abstracto de onde o rigor se extrai (esse essentiae).

Cf. sobretudo DECORTE, J. - "Modus...", 407-29.

${ }^{34}$ Cf. CARVALHO, M. S. de - "Sobre o Projecto do Tratactus de Productione Creaturae de Henrique de Gand", Mediaevalia. Textos e Estudos (no prelo). Para uma interpretação de S. Tomás que revaloriza a noção de relação enquanto integradora dos vánios elementos constituintes da noção de pessoa (e portanto para uma leitura menos essencialista), vd. EMERY, G. - "Essentialisme ou personnalisme dans le traité de Dieu chez saint Thomas d'Aquin?", Revue Thomiste 98 (1998), 5-38.

Cf. BRETON, S. - Philosophie et Mystique. Existence et surexistence, Grenoble, 1996, 103-104. 
A radical temporalidade da criatura imita Deus como Seu produto livre e a dependência causal que se instaura é chamada a reproduzir no tempo e na história a progressiva tendência que todo o exemplificado tem para imitar o exemplar. Razão pela qual o esse que rege 0 ablativo (esse $a b$ ) pode perfeitamente ser lido em português pelo esse que rege acusativo (esse ad), do ser-para. Que esta tendência não é meramente psicológica mas assenta na própria estrutura do esse $a b$ altero, não se há-de ver apenas pela crítica à teoria aristotélica e tomasina da relação fundadora de uma ontologia dinâmica. Muitas outras maneiras eram possíveis, mas limitar-me-ei, para finalizar, ao estatuto da individuação. É o caso em que a pergunta pela natureza do homem se concretiza na pergunta pela "natureza" do sujeito ou de um indivíduo singular. O que me faz sujeito? Eis uma pergunta nuclear para a antropologia.

Em muitos lugares da sua obra o teólogo flamengo opõe-se à importância da matéria na individuação. Também a sua participação no caso 1277 e o topos teológico de Cristo no tríduo (estudado já há muito por $\mathrm{P}$. Bayerschmidt ${ }^{36}$ ) não é menos relevante e determinador dessa importância na medida em que Cristo é, afinal, o homem por excelência.

Tomemos o Quodlibet IV, q. 4, no qual Henrique enfrenta o conceito de natureza (natura) contrastando-o com o de supósito (suppositum). Este dirá respeito ao homem existente (id cuius est) aquele à humanidade que o determina (quod quid est). ${ }^{37}$ Reconhecemos, naturalmente, a diferença nuclear e programática entre existência (esse existentiae) e essência (esse essentiae). Ora, a resposta do autor é a de que na ordem dos concretos unissingulares natureza e supósito identificamse. (Como se sabe, uma das estratégias mentais de Henrique passa pela recorrente negação da diferença real e mental, propondo em alternativa uma diferença intencional, a qual, obviamente, responde directamente à teoria criacionista. ${ }^{38}$ ) Todavia, se o plano da natureza e o do supósito (universal, no caso, i. e., o da espécie) se multiplica pelos indivíduos, como entender essa individuação? Como multiplicação? Ao recusar a tese anistotélico-tomista da individuação pela forma material (Q. 5, 8, f. $165 \mathrm{rL}-165 \mathrm{vL}),{ }^{39}$ o que Henrique está a afastar é uma posição filosófica que equaciona a diferença ontológica mediante a (i-materialidade) tomando posição perante a temática substancialidade/acidentalidade. Como neste

36

37

38

39

Cf. BAYERSCHMIDT, P. - Die Seins - und Formmetaphysik des Heinrich von Gent in ihrer Anwendung auf die Christologie. Eine philosophie - und dogmengeschichtliche Studie, Muenster, 1941.

Cf. WILSON, G. - "Supposite in the Philosophy of Henry of Ghent", in Henry of Ghent. Proceedings..., 361 .

Cf. MACKEN, R. - "Les diverses applications de la distinction intentionelle chez Henn de Gand", in Sprache und Erkenntnis im Mittelalter, Berlin, 1981, II, 769-76; CARVALHO, M. S. de - "Sentido e Alcance do pensamento de Henrique de Gand. Explicação da nona questão do 'Qudolibet' I: a relação essência/existência", Mediaevalia. Textos e Estudos 3 (1993), 161-205; PORRO, P. - "Possibilità...", 216, n. 14 com mais bibliografia.

Cf. BROWN, M. - "St. Thomas Aquinas and the Individuation of Persons", American Catholic Philosophical Quaterly 65 (1991), 29-44, para uma conjugação dos três factores que determinam a individuação: matéria, existência e a alma racional. 
momento está adquirido, também poderíamos substituir "substancialidade" por "relacionalidade". A essência do diferir passa pela prévia determinação metafísica da criaturalidade, estratégia que nos pareceria correctíssima acaso ela não se perdesse uma vez mais em geométricas distinções e, em contrapartida, tivesse da conaturalidade uma acepção mais ampla. A diferença ontológica determina-se na/pela distinção entre Criador e criatura, etemidade e tempo, necessidade e contingente, substância (subsistência) e acidente, ser-em-si como ser-para vs. serem-outro.

A solução adoptada para explicar a individuação é a conhecida teoria da dupla negação: negação da multiplicidade e diversidade interior e negação de qualquer identidade exterior, $a b$ intra omnem plurificabilitatem et diversitatem, et $a b$ extra omnem identitatem (Q. 5, 8, f. 166rM). Eis uma formulação, pela negativa, da independência ontológica de um ente relativamente a todos os outros. $\mathrm{E}$ descendo ainda mais ao pormenor: no mesmo lugar $(165 \mathrm{r} \mathrm{K})$ Henrique escrevia ser preferivel (potius) defender que os acidentes se individuam na substância (per substantiam) do que as substâncias pelos acidentes (per accidentia). ${ }^{40} \mathrm{Um}$ entendimento tão formal da individualização é surpreendente na sua mera gramaticalidade ou sistematicidade, pelo que nos devemos perguntar, inclusive, se, então, um indivíduo não corre o risco de ser um fragmento singular de um sistema de algum modo impotente para uma determinação absoluta fora do quadro desse sistema abstracto, real mas inexistente. Pode, ainda, ligar-se a teoria da dupla negatividade com o processo da acidentalidade e dizer (0. 5, 8, f. 166rM) que aquela "negação ou determinação, embora não acrescentando nada de real naquilo que se separa, além da essência que o determina, uma vez que está fora da noção de forma, enquanto forma, pode dizer-se, numa acepção lata de 'acidente' que é um acidente, porquanto a sua individuação se dá por um acidente superveniente à forma, pois as formas materiais comportam um acidente que é a quantidade na matéria que os individua." ${ }^{41}$ A noção lata de acidente é, obviamente, a de Avicena ou também, como apressadamente reconhece o autor (0. 10, 7, p. 157-58), de Algazel e de Averróis, ${ }^{42}$ i. e., não aquela em conformidade com a qual ao ser algo de real se acrescenta (era esse antes o alcance da symbebekos aristotélica) mas antes graças à qual um ser passa a existir (0. 1, 9, p. 54). ${ }^{43}$ Uma lição a reter é, evidentemente, a de que nos seres materiais será um erro equiparar a individuação pela

40 Será preciso observar que Henrique bebe em Avicena uma concepção lata de "acidente" assim apresentada (Q. 2, 8, p. 48): "[...] 'accidens' accipitur hic largissime, secundum quod iuxta modum loquendi Avicennae 'accidens' rei appellatur omne quod convenit ei et est extra intentionem suae essentiae." Voltaremos aqui já a seguir.

Q. 5, 8, f. 166rM: "Et quia talis negatio sive determinatio, licet nihil rei apponit in separatis supra essentiam qua determinetur, in quantum tamen est extra intentionem formae, ut forma est, large sumendo accidens potest dici accidens, ut secundum hoc huiusmodi individuatio dicatur fieri per aliquod accidens formae superveniens, cum tamen formae materiales habeant aliquid accidens scilicet quantitatem in materia, qua individuentur."

42 Na recentemente descoberta "redactio altera" desta questāo, que alegadamente, segundo o seu editor, restitui uma primeira redacção do próprio autor de $0.10,7$, não surge esta referência autoral, vd. LUNA, C. - "Nouveaux textes d'Henri de Gand, de Gilles de Rome et de Godefroid de Fontaines. Les questions du Manuscrit Bologne, Collegio di Spagna, 133. Contribution à l'étude des Questions Disputées", AHDLMA 65 (1998), 151-272, especialmente 186, 220-36. 
matéria esquecendo a forma ou pela forma esquecendo a matéria (S. 28,5, f. $168 \mathrm{v}$ B), mas uma vez mais não há que interpretar isto na linha do tomismo para o qual algo passa a existir pela recepção de um acto de ser pela essência que se finitiza materialmente. Recusada a individuação pela matéria, Cálias é Cálias porque: 1) não é Sócrates e é irreprodutível nessa não-identidade (independência ontológica); 2) na sua essência de homem-Cálias (a finitude metafisicamente instaurada), que se identifica realmente com Cálias-homem, a passagem daquela a este é acidental ou, de outra maneira, ele torna-se este homem concreto Cálias por uma alteração na sua substância (o plano lógico-metafísico que o funda) alteração essa que não ocorre sem um entendimento da passagem à existência (Criação) por decisão sobre a necessidade de um conteúdo ou um correlato fundador. É evidente que é neste ponto particular que a doutrina de Henrique de Gand se torna mais fecunda, também a nosso ver, na medida em que permite a ligação entre a individualização e a contingência ou a liberdade. Mas o nosso propósito presente não era este, como avisámos logo de início. Retenha-se, então, relativamente a toda esta articulada correlação natureza (essência) e supósito (concreto), o seguinte: um indivíduo - seja Cálias, de novo - individua-se como Cálias graças à possibilidade de multiplicação do que é universal (a espécie a que pertence) e pela individuação da essência, a humanidade, da qual participa singularmente (S. 32, 5, p. 114-15). Convenhamos que esta maneira de responder à pergunta sobre o que me faz indivíduo, ou sujeito como diríamos hoje, revela a existência de uma aptidão ou disposição natural para a independência ou incomunicabilidade ontológica, i. é., uma tendência natural para existir num suposto determinado, para existir, enfim, como pessoa. Mas o estabelecimento metafísico desta existência ou o seu processo de fundação procede à determinação da necessidade da relação numa gramática que se sobrepõe à existência da relação no sentido de relação como existência. Uma investigação sobre a realidade da relação que esqueça a relação enquanto existente não pode ter do indivíduo ou da pessoa humana uma leitura integral ao amputar mais ou menos a quota-parte da relação física, sensivel, humana e aleatória. Longe de pôr em causa toda a importância daquele legado, quisémos aqui atermo-nos apenas à sua determinação lógica.

\section{0}

Quer no caso da relação quer no da individuação, Henrique demorou-se requintadamente e não sem dificuldades numa complexa teia de elucubrações, numa rede abstracta e presumivelmente fundadora. Mas qual foi o modo dessa fundação? Parece-nos que, no quadro metafísico que apenas lembrámos e que se deveria sempre correlacionar com o pendor temporalista do Gandavense, a resposta só pode apontar para o privilégio do necessário e do dedutivo como gramática de uma antropologia nos limites da pura razão (teológica). Tomando uma grande liberdade para com o texto de Kant ( $\mathrm{KrV}$ A 632/ B 660) ousariamos reinventar a expressão "ontoteoantropologia" para designar esta aproximação que julga conhecer a existência do homem por simples conceitos sem a passagem pela experiência. Isso mesmo sucedia, v. gr., com a tashakhkhus (individuação) avicénica (Isharat II): mediante uma interacção de causas e elementos metafísicos que 
são o correlato da forma como Deus conhece as criaturas individuais, de acordo com este modelo, Deus conheceria os indivíduos através de um complexo universal de relações causais definidores do termo próprio e do modo próprio da existência individual. Tratava-se, porém, de um conhecimento formal relativo não ao indivíduo em si mesmo, considerado como um verdadeiro eu, com suas hesitações, dúvidas e perplexidades, mas sobretudo ao seu desempenho histórico e coexistencial (com o consequente predomínio do tom casuístico e deontológico descortinável na literatura henriquina de moral aplicada).

Diferente seria o modelo plotino-augustinista em que é de facto um eu que está em jogo. Recordemos como para Plotino é possivel a presença de Nous na ideia inteligível de cada indivíduo, de cada eu. Nas Enéadas V, 7, 1 é o eu, não o eu físico de Aristóteles, mas o eu-pessoa (ego), que procede anagogicamente para 0 inteligível onde reside o princípio de cada ser individual e a narratividade poética augustinista descreve-nos um processo histórico e vivencial de um homem interior(izado) buscando Deus. É que as fontes do próprio (self) não são indissociáveis de uma permanente ou sempre em aberta procura de significação sobre as coisas que me acontecem. É que - insistimos com Plotino - Nous comporta em si a unidade dos inteligíveis que se reflectem entre si, ocorrendo na Inteligência uma identidade entre os inteligíveis e o que nela os pensa; é porque "cada inteligível, tomado em si mesmo, não é uma ideia abstracta, mais pobre do que as realidades concretas existentes das quais a inteligência seria extraída, mas, ao contrário tem em si toda a riqueza do mundo sensível inferior, embora de um modo imaterial" ".4

Ora, se confrontarmos o homem interior augustinista com o sujeito desencarnado cartesiano (dois momentos-chave na história modema do eu) temos que reconhecer que qualquer coisa se passou entretanto. Procurámos apenas evidenciar um sintoma neste processo e ele é precioso pela exemplificação que dá de uma razão (teológica) exercitadamente "pura", capaz de dedutivamente fundar por distinções subtis a natureza de um homem que perdeu o contacto com a natureza a que também pertence. Foi este o preço a pagar pela correcção do augustinismo com base (entre outros) no fecundo avicenismo em que a natura modela sem ser ela própria naturalmente modelada ou modelável.

4 Cf. ARNALDEZ, R. - Trois Messagers pour un seul Dieu, Paris, 1991, 133. 